\title{
LVII. On phosphuretted hydrogen
}

\section{Thomas Graham F.R.S.}

To cite this article: Thomas Graham F.R.S. (1834) LVII. On phosphuretted hydrogen , Philosophical Magazine Series 3, 5:30, 401-415, DOI: 10.1080/14786443408648497

To link to this article: http://dx.doi.org/10.1080/14786443408648497

册 Published online: 01 Jun 2009.

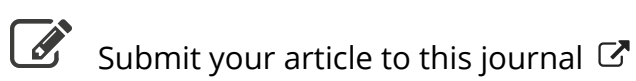

LII Article views: 2

Q View related articles $₫$ 


\title{
LONDON AND EDINBURGH
}

\section{PHILOSOPHICAI، MAGAZINE}

\author{
A ND \\ JOURNAL OF SCIENCE. \\ [THIRD SERIES.] \\ $D E C E M B E R \quad 1834$.
}

LVII. On Phosphuretted Hydrogen. By Thomas Graham, F.R.S. Edin., Andersonian Professor of Chemistry, and Vice-President of the Philosophical Society of Glasgorw.*

$\mathrm{F}_{\mathrm{EW}}$ substances have been made the subject of experimental inquiry more frequently than the compounds of phosphorus and hydrogen, and none are so remarkable for the various and conflicting results which they have presented to chemists of the greatest acuteness and practical skill. The obscurity which long hung over the subject has been dispelled, however, in a great measure, by the recent investigations of Henry Rose, of Berlin t. Although baffled in his early inquiries, that philosopher returned again and again to the subject, and at last succeeded in determining the chemical functions and true constitution of phosphuretted hydrogen. He has shown it to be analogous to ammonia in chemical character and composition. But hitherto two compounds of phosphorus and hydrogen had generally been admitted to exist, which were believed to differ in composition as they do in properties, one being spontaneously inflammable in atmospheric air, and the other not so. Rose establishes beyond all doubt that these gases are essentially of the same composition, and of the same specific gravity; and, indeed, that they are mutually convertible, each into the other, without any

* Communicated by the Author.

+ An account of Rose's experiments on this subject, with a notice of Dr. Dalton's anticipation of his views, will be found in Lond. and Edinb. Phil. Mag. vol. iii. p. 308.-EDit.

Third Series. Vol. 5. No. 30. Dec. 1834. $3 \mathrm{~F}$ 
addition or subtraction of matter that could be perceived. In explanation of their possession of different properties, under the same composition, allusion is made by Rose to isomerism, or the doctrine that two borlies may exist identical in composition, but differing in properties. Certainly the existence of two gases constituted alike, and yet possessing different properties, if established, would afford a firm basis for this doctrine.

It was the importance of the theoretical results which might be looked for, that induced me to attempt to continue the investigation beyond the point to which it has been carried by Rose. Holding the general doctrine of isomerism as problematical, my inquiries were directed to the discovery, in one or other of the gases, of some adventitious matter, to the presence of which the peculiarities of the species might be attributed.

It is to be understood that the spontaneously inflammable gas made use of in my experiments was prepared by the well-known process of heating phosphorus, lime, and water together. This gas is spoken of as " the self-accendible gas," or as " the gas from phosphuret of lime." The other gas, which is not spontaneously inflammable, was prepared by heating hydrated phosphorous acid, or by allowing the preceding species, contained in low receivers, to stand over water for twenty-four hours. It is described as " the non-accendible gas," " the gas from phosphorous acid." The accendibility of the gas was judged of by allowing it to escape in bubbles into the air from the receiver containing it, over either water or mercury. The experiments were all made when the temperature of the atmosphere was between $60^{\circ}$ and $70^{\circ} \mathrm{Fahr}$.

1. In the process by which the self-accendible gas is procured, free phosphorus distils over, of which a trace in the state of vapour may well be supposed to remain in the gas for some time. Hence the idea has generally presented itself that the free and highly accendible phosphorus present may be the cause of the spontaneous inflammability of the gas. Dr. Dalton, who all along maintained the opinion, which has finally been established by Rose, that the two gases are of the same composition, was in the habit of referring the spontaneous inflammability of the one species to this cause. The speedy loss of the property in question in the case of gas confined over water seemed to favour this view. I find, however, that if a small quantity of phosphuretted hydrogen, when not self-accendible, be added to a confined portion of air, sticks of phosphorus introduced into that air do not smoke,-or that phosphorus has no disposition to combine with oxygen when phosphuretted hydrogen is present. In a transparent mixture 
of one volume phosphuretted hydrogen, and one thousand volumes, or any smaller proportion whatever, of air, sticks of phosphorus remain unaffected, but the phosphuretted hydrogen itself always undergoes a slow oxidation. In a mixture of one volume phosphuretted hydrogen and two thousand air, phosphorus smoked strongly for some time, but at a certain period the action ceased, and long before the oxygen of the air was exhausted. A minute proportion of phosphuretted hydrogen is, therefore, sufficient to protect phosphorus from oxidation, in which respect this gas resembles the hydrocarburets and essential oils, which have been shown to be equally efficacious in protecting phosphorus from oxidation. All these bodies appear to act in this respect in one way, namely, by taking the precedence of phosphorus in the process of oxygenation. Phosphorus being, therefore, less oxidable than phosphuretted hydrogen itself, cannot be supposed to take fire, and to influme the gas, or be the cause of its accendibility at low temperatures.

On sending electric sparks through non-inflammable phosphuretted hydrogen itself, phosphorus is deposited; but the gas, while still cloudy from the phosphorus suspended in it, proved to be non-inflammable on passing it into air.

The loss of accendibility in the case of gas confined over water is certainly wholly unconnected with the deposition of any free phosphorus from the gas which may occur, but is due to the rise of oxygen from the water into the gas. It was observed that water which had been boiled to deprive it of all air, and which was then passed up to self-accendible gas confined over mercury, did not affect the gas in the course of forty-eight hours. In this case, moreover, the gas was agitated with the water. The gas continues in general spontaneously inflanmable over mercury for forty-eight hours, and sometimes for three or four days, but ceases to be so in a very short time after the admission of a small proportion of air, particularly if the air be added in a gradual manner. Thus, if to the gas be passed up one twentieth part of its bulk of cork or dry stucco, containing air in its pores, a white smoke appears in the gas, and it ceases to be spontaneously inflammable in the course of a few minutes. The same mass of stucco, warmed before being passed up into the gas, did not produce the same effect. The self-accendible gas al ways deposits on standing a solid matter of a lively yellow colour, containing phosphorus, but in quantity too minute for analysis. This matter is not acted on by any of the ordinary solvents, such as alcohol, æther, alkalies, muriatic acid; but is destroyed by chlorine-water and by nitric acid. The precipitation of this matter is most rapid in the case of gas over water, and is inclicative of deterioration of the gas. 
2. The self-accendible gas procured from phosphorus, water, and lime, is always mixed with free hydrogen, varying in quantity from 25 to 50 per cent., while the non-accendible gas from phosphorous acid contains no hydrogen gas, but is pure. Rose concludes, that the spontaneous inflammability of the first species cannot depend upon this hydrogen, for the other species is not made self-accendible by the addition to it of any proportion of free hydrogen. On trying the experiment, however, I obtained a different result. A quantity of gas had lost its self-accendibility by standing over water for two or three hours. To my surprise the addition to this gas of hydrogen, in any proportion from one third of a volume to three volumes, restored the self-accendibility of the gas. Spontaneous inflammability was communicated likewise to the gas procured from phosphorous acid, in some cases, merely by adding hydrogen to it. It was perceived, however, early in the course of the investigation, that hydrogen did not uniformly communicate the property in question, and that its influence depended on something accidental, and not essential to the gas. For instance, the hydrogen which comes over almost pure, towards the end of the process for phosphuretted hydrogen, itself had none of this property; nor did it appear in hydrogen obtained from the following sources: From the electric decomposition of water; from the decomposition of steam by iron; from the action of water on amalgam of potassium ; or from the action of the following acids on zinc, namely, muriatic, arsenic, and phosphoric. Even in the case of the action of sulphuric acid on zinc or iron, which had first afforded hydrogen possessing the property in question, it turned out that only the hydrogen evolved at an early period of the action is efficient, while the gas evolved after the vivacity of the action is impaired, is nearly, and sometimes entirely, destitute of any influence. The activity of the hydrogen was, in short, traced to a slight impregnation of nitrous acid vapour which it possessed. The sulphuric acid of commerce always contains a small portion of some acid of nitrogen, probably the hyponitrous, from which I find it cannot be freed by boiling or concentration, continued for any length of time. On quickly mixing sulphuric acid with two or three volumes of water, the presence of nitrous acid is attested by its pecnliar odour, and almost certainly by the appearance of brown fumes.

That the hydrogen did not owe the property in question to a trace of nitric oxide, which, combining with oxygen, might by a slight consequent evolution of heat have an effect in kindling the phosphuretted hydrogen, was proved by the fact that the property in question could not be imparted to hydrogen by any proportion of nitric oxide : but to this point there 
will be occasion to recur. At an earlier stage in the inquiry, some experiments were made upon the effect of other gases than hydrogen upon phosphuretted hydrogen. None, with the exception of sulphuretted hydrogen, (evolved by the action of sulphuric acid on sulphuret of iron; and which, therefore, contains free hydrogen,) appeared to favour the accendibility of the gas. On the contrary, the addition of all others, and even of hydrogen and sulphuretted hydrogen themselves above a certain proportion, distinctly impeded or destroyed the accendibility of this gas. Thus, one volume phosphuretted hydrogen ceased to be inflammable when mixed with the following proportions of different gases:

With 5 volumes hydrogen.

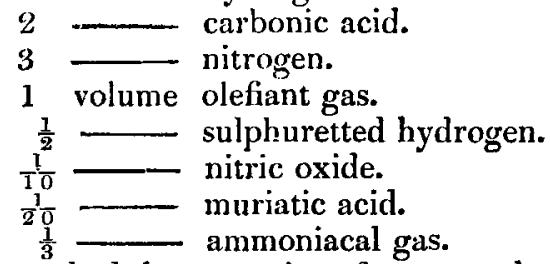

It is to be remarked, however, in reference to the preceding table, that some specimens of phosphuretted hydrogen appear to be more highly accendible than others, and that there is considerable latitude in the proportion of foreign gas which may be requisite for destroying the spontaneous inflammability of a given specimen. Often a much smaller portion suffices than is stated in the table. I have found half a volume of carbonic acid or nitrogen to have the effect in certain cases. Of course the introduction of any trace of air with the gases must be carefully guarded against. Nitrous acid, when present in hydrogen in too small a proportion to enable that gas to communicate spontaneous inflammability to phosphuretted hydrogen, or to be perceived by the smell, may be detected by the effect of the hydrogen upon a prepared mixture of non-accendible phosphuretted hydrogen and air, which mixture may be had transparent and quite free from white smoke. The addition of hydrogen to this mixture occasions the immediate appearance of a dense white smoke, the oxidation of the phosphorus being partially induced if an infinitesimal proportion even of nitrous acid exist in the hydrogen. Although the oxidation of the phosphorus takes place at the expense of the air present, and only when air is present, yet the nitrous acid appears to be speedily consumed; the fumes soon ceasing, but appearing again on every subsequent addition of active hydrogen, till several volumes have been added, or till the oxygen of the air present is exhausted.

That the influence of the hydrogen was referrible to the ni- 
trous impregnation appeared also from the fact, that phosphuretted hydrogen, which had lost its spontaneous inflammability, was rendered as actively inflammable as ever by passing it, bubble by bubble, into an inverted receiver filled with sulphuric acid recently diluted with three measures of water and cooled. The gas was now capable of igniting spontaneously when passed into air, without the intervention of hydrogen. The same diluted acid lost the smell of nitrous acid by exposure to air in a shallow vessel for a few hours, and thereafter was found unfit for the purpose in question. Phosphuretted hydrogen which had acquired spontaneous inflammability from a nitrous impregnation, appeared to retain that property as long as the phosphuretted hydrogen which is spontaneously inflammable as first prepared. Hydrogen gas which had received a nitrous impregnation by being passed through a diluted sulphuric acid, retained in one case, after being confined for twenty-four hours over water, the power of rendering phosphuretted hydrogen spontaneously inflammable.

From the preceding results and other considerations, it seemed not unlikely that the spontaneous inflammability of phosphuretted hydrogen may be an accidental property, and may depend upon the occasional presence of some foreign body in minute quantity. 'The inquiry suggests itself, Is there a peculiar principle in the self-accendible gas? and if so, what is it?

3. It very soon appeared that a peculiar principle is withdrawn from the gas by porous absorbents, such as wood-charcoal and baked clay, which substances are capable of destroying the inflammability of several hundred times their volume of gas. Thus, in one experiment, to five hundred measures of highly accendible phosphuretted hydrogen, one measure of charcoal recently heated to redness, and cooled under the surface of mercury, was passed up. In the course of five minutes, a contraction of eight or ten measures occurred, without any oxidation of the gas, for no air was introduced with the charcoal. The gas was still spontaneously inflammable, but ceased to be so in the course of half an hour. It was found, in fact, by different experiments, that wood-charcoal can absorb about ten times its volume of phosphuretted hydrogen itself; that the phosphuretted hydrogen and the peculiar principle are absorbed indiscriminately at first by the charcoal, but that by and by the peculiar principle comes to be entirely absorbed by the charcoal without any further absorption of phosphuretted hydrogen. When the phosphuretted hydrogen did not exceed fifty or sixty times the bulk of the charcoal, the peculiar principle was entirely withdrawn 
in five minutes, so that the gas censed to be self-accendible. Charcoal which had been drenched in water was without effect upon the gas. On heating the charcoal saturated with gas in a retort filled with water, phosphuretted hydrogen was given off, which, however, was not self-accendible; and all my attempts failed to isolate the peculiar principle by sepam rating it from the charcoal. It was quite clear that the peculiar principle formed but a very small proportion of the phosphuretted hydrogen, evidently much less than one per cent. of the bulk of the gas. Spongy platinum introduced into the gas did not exercise any sensible absorbent effect, and no quantity of it seemed sufficient to withdraw the peculiar principle from a small bulk of phosphuretted hydrogen. Stucco, likewise, was without effect upon the gas, at least when access of air was guarded against at the same time. But both of these substances are known to possess a very low absorbent power.

4. Phosphuretted hydrogen transferred to a receiver over mercury, the inside of which has been moistened by a solution of caustic potash, always loses its spontaneous accendibility, although by no means rapidly, several hours being generally required.

5. Certain acids appear to have a remarkable power in withdrawing the principle of inflammability from phosphuretted hydrogen. Let phosphuretted hydrogen be transferred into a jar inverted over mercury, of which jar the inner surface has been moistened with concentrated phosphorous acid. A small quantity of the milk-white matter immediately appears in the acid where exposed to the gas, and in two or three minutes the gas has ceased to be spontaneously inflammable in air, without any appreciable diminution of its volume having occurred. This white matter, although very sensible to the eye, exists only in the most minute quantity. It is not crystalline, and perhaps not even solid. The introduction of concentrated phosphoric acid into the gas was attended by similar phænomena, and the gas lost its spontaneous inflammability in the course of half an hour. A strong solution of arsenic acid acts as rapidly in withdrawing the peculiar principle as phosphorous acid does; but the arsenic acid soon begins to react upon the phosphuretted hydrogen itself, a dark copper-coloured incrustation soon forming upon the surface of the gas-receiver, which matter is probably a phosphuret of arsenic. Concentrated sulphuric acid is capable of absorbing phosphuretted hydrogen itself, which the preceding acids are not; but even sulphuric acid appears to absorb the peculiar principle in the first instance, by a more active affinity than 
it exerts on the gas itself. Diluted phosphorous, phosphoric and arsenic acids react in the same manner upon phosphuretted hydrogen, but not so rapidly as the concentrated acids do.

6. The following liquids are capable of dissolving the quantity of phosphuretted hydrogen gas placed against their names at $65^{\circ}$ Fahrenheit.

$$
\begin{aligned}
& \text { Alcohol (sp. gr. 850) } \\
& \text { Sulphuric æther...... } 2^{\frac{1}{2}} \text { volume. } \\
& \text { Oil of turpentine ..... } 3 \frac{1}{4}
\end{aligned}
$$

The essential oils and most of the hydrocarburets appear to withdraw or to negative the peculiar principle in spontaneously inflammable phosphuretted hydrogen, in a rapid manner. If a jar be moistened in the slightest degree with oil of turpentine, coal-tar naphtha, or with the liquid distilled from caoutchouc, and then be used as a receiver for containing self-accendible gas over either water or mercury, the gas is found to lose its spontaneous inflammability in a few minutes. White fumes often appear in the gas at the same time; but these, I am satisfied, are due to the evolution of some gaseous oxygen from the liquids, and only occur in the case of the portion of gas which is first brought into contact with the liquid, and do not appear in the case of subsequent additions of gas, although the liquid remains capable of destroying the spontaneous accendibility of many portions of gas successively exposed to it. It is not easy to decide whether these vapours destroy irrecoverably the peculiar substance of spontaneous inflammability, or merely negative the action of that principle by their presence. I am inclined to think, however, that they destroy that principle, for the action is not so rapid as the diffusion of the vapour through the gas, the impregnation appearing to be fully accomplished, and yet the loss of inflammability not occurring sometimes for two or three minutes afterwards; particularly in the case of naphtha; a portion of that pure liquid in which potassium had been preserved being used in the experiment. A small addition of ather vapour also destroys the inflammability of phosphuretted hydrogen, although a distinct period must elapse before the change occurs, such as a quarter of or half an hour. The action of alcohol vapour is much slower, generally requiring two or three hours. Pure olefiant gas, containing no air, added in the proportion of ten or twenty per cent., eventually destroys the spontaneous inflammability, but requires a period of not less than twenty or thirty hours. Olefiant gas has a negative influence of quite a different character, which has already been alluded to, and which is in action the moment the gases are 
mixed, but which does not appear unless the proportion of olefiant gas be very considerable. It is probable that ather vapour and the gaseous hydro-carburets have an influence of the same kind. An astonishingly minute quantity of an essential oil suffices to destroy the inflammability of the gas over mercury, if allowed an hour or two to act. Hence it is very difficult to preserve gas in the inflammable state in the mercurial trough, if any portion of the mercury has been soiled by an essential oil.

7. The action of potassium on the peculiar principle is equally remarkable. A most minute quantity of this metal or of its amalgam destroys the self-accendibility of the gas in a few minutes, without occasioning any reduction of volume that could be measured. The fact is, that potassium or its amalgam is without effect upon phosphuretted hydrogen itself at the temperature of the air, neither absorbing nor decomposing the gas; but upon the peculiar principle, the action of this metal is rapid and certain. One grain of potassium amalgamated with fifty pounds of mercury rendered that quantity of mercury quite unfit for retaining gas over it in an inflammable condition for more than a few minutes. In such experiments the interference of naphtha vapour was perfectly excluded. Zinc and tin, either by themselves or in the state of amalgam, have no sensible effect upon the self-accendible gas, at least in a period of five or six hours. Protoxide of mercury speedily withdraws the peculiar principle, but afterwards also reacts slowly upon the gas itself. On the other hand, the peroxide of the same metal is in no way injurious to the self-accendible gas. Arsenious acid in powder acts in the same manner as protoxide of mercury. The solution of protosulphate of iron, if previously boiled, to deprive it of air, is without effect upon the gas. The extraordinary action of potassium, and that also, perhaps, of the essential oils, seemed to point to the existence of an oxygenated principle as the cause of the spontaneous inflammability of phosphuretted hydrogen. It is sufficiently evident that the proportion in which this principle exists, to the whole gas, is exceedingly small, too minute to afford any hope of isolating the principle. The nitrous impregnation, too, which was found adequate to render gas spontaneously inflammable, shows to how minute a quantity of matter the spontaneous inflammability of phosphuretted hydrogen may, at times, be owing. It seemed within the bounds of possibility that the gas might owe its spontaneous inflammability in ordinary circumstances, if not to nitrous acid, at least to some other principle allied to that substance. This led to a careful re-

Third Series. Vol. 5. No. 30. Dec. 1834 . 3 G 
examination of the properties of phosphuretted hydrogen made inflammable by means of nitrous acid; a subject of much interest, as illustrating the effect of a most minute and almost infinitesimal quantity of foreign matter in communicating to a chemical body so striking a property as spontaneous inflammability. Independently of the light which it may throw upon the constitution of ordinary phosphuretted hydrogen in reference to that property.

8. Phosphuretted hydrogen which had lost all trace of spontaneous inflammability by standiug a day or two over water, or the gas from hydrated phosphorous acid, could be impregnated with nitrous acid and made spontaneously inflammable in various ways. It was ascertained that the gas obtained by either process was affected in the same way. Such gas only, entirely destitute of spontaneous inflammability, was employed in the following experiments.

(1.) The nitrous acid of Dulong may be added directly to the gas over mercury; a glass spherule, or the bore of a short piece of thermometer tube, being filled with the liquid, and passed up to the gas. When nitric acid is brought into contact in this manner with the gas, a violent action ensues, but with nitrous acid the evolution of white fumes is very slight. The nitrous acid is absorbed in part by the mercury, but this absorption is slow, provided the quantity of gas with which the acid vapour is mixed be considerable. If the quantity of gas primarily impregnated with nitrous acid in the manner described be small, or the impregnation of nitrous acid considerable, the gas exhibits no disposition to smoke or to take fire when passed into air. It has not become spontaneously accendible. On diluting the gas with a large proportion of unimpregnated phosphuretted hydrogen, no reaction is indicated, but the whole becomes spontaneously inflammable in a high degree. In fact, it was discovered that the gas is not accendible when the nitrous acid exceeds a certain proportion, which is by no means considerable.

(2.) Allow a single drop of nitrous acid to fall into a dry glass jar, which may be of small dimensions: fill the jar with mercury, and invert it, without loss of time, in the mercurial trough. A bubble of gas will collect in the upper part of the jar, which bubble is chiefly nitrons acid vapour. One cubic inch or so, of phosphuretted hydrogen, or of hydrogen itself, may then be added to the gas in the jar; and this is our nitrous impregnating mixture: suppose this mixture to contain one twentieth of its bulk of nitrous acid vapour; the addition of it in any proportion to phosphuretted hydrogen is not attended by the slightest production of white fumes; in fact, no 
reaction appears to take place. But the addition of a single bubble of this mixture, not exceeding one tenth of an inch in volume, to five or six cubic inches of phosphuretted hydrogen will render the whole highly accendible, so that every bubble passed into the air will take fire.

(3.) In the last arrangement a drop of the strongest nitric acid may be substituted for the nitrous acid, in the preparation of the impregnating mixture. The nitric acid acts on the mercury, and nitric oxide charged with nitrous acid vapour is collected, which may be diluted with hydrogen as above.

The preceding processes uniformly afford a nitrous impregnating mixture which may be depended upon; but when the experiment is attempted over water, there is not the same certainty of the impregnation being successful. I have often, however, made hydrogen highly suitable for the purpose, by passing it through a column of fluid composed of nitric acid recently diluted with water, provided that the acid had been fuming from the presence of nitrous acid; or by passing hydrogen through recently diluted sulphuric acid, as has already been stated.

In regard to the proper proportion of nitrous acid vapour to the phosphuretted hydrogen, I am satisfied that the proportion most efficacious is somewhere between one part nitrous acid to one thousand, and one to ten thousand phosphuretted hydrogen. One nitrous acid to one hundred gas, or less gas, is never accendible, but becomes so on diluting it with enough of phosphuretted hydrogen.

I was anxious to discover how far nitric oxide interferes in the phænomena. The nitrous acid is never free from, but is always accompanied with, a certain proportion of this gas.

9. Action of Nitric Oxide.-In a table formerly given (p. 405.), nitric oxide is set down as preventing the accendibility of the good gas from phosphuret of lime, when the proportion of the first is so great as one tenth of the whole mixture. In fact, the best inflammable gas when mixed with nitric oxide in quantity from two volumes to one tenth of a volume, exhibited no symptom of spontaneous inflammability. The nitric oxide forms red fumes when the mixture meets the air, but the phosphuretted hydrogen does not even smoke; so that the oxidation of the nitric oxide las not a kindling effect upon the phosphuretted hydrogen, but the very reverse. A mixture of one volume nitric oxide with twenty volumes of good phosphuretted hydrogen (self-accendible per se) is still selfaccendible; the bubble, however, does not take fire the instant it bursts in the air, but after rising to a little height, and then 3 G 2 
it explodes with a puff, like loose grains of gunpowder, and not with the usual snap, the oxidation of the nitric oxide preceding by a sensible interval the oxidation of the phosphuretted hydrogen. Nitric oxide in a considerably smaller proportion than $\frac{1}{20}$ th of a volume exhibits a sensible effect in retarding the combustion of self-accendible gas, but does not altogether prevent it.

In the case of phosphuretted hydrogen which was not selfaccendible, small additions of nitric oxide, such as one to one hundred, to five hundred, to one thousand, or to two thousand volumes phosphuretted hydrogen, did not induce self-accendibility when the nitric oxide employed had been previously washed with caustic alkali. The experiment was tried with three different specimens of washed nitric oxide. But nitric oxide which had not been washed with alkali, particularly if it resulted from a turbulent action of the nitric acid on copper, and came over charged with red fumes, and was withal newly collected, was pretty often efficient in making the gas self-accendible. The proper proportion of such nitric oxide for this purpose was found to be one volume to a quantity between thuse of one thousand and two thousand volumes of phosphuretted hydrogen. A greater or a less proportion of the nitric oxide failed to produce the desired effect. All these experiments with nitric oxide were made over water.

It is well known that a mixture of phosphuretted hydrogen and nitric oxide may be exploded by a bubble of oxygen gas, a method of firing these gases first practised, I believe, by Dr. Thomson. But Dr. Oalton found pure nitric oxide capable of oxygenating phosphuretted hydrogen in a gradual manner when the two gases are left together, nitrous oxide and nitrogen resulting. Possibly, therefore, it is by acting itself upon phosphuretted hydrogen that nitric oxide prevents atmospheric air from acting upon that gas in our experiments. It is conceivable that the oxygenating action of nitric oxide upon phosphuretted hydrogen may be promoted, like that of air upon the same gas, by the presence of nitrous acid, which will explain Dr. Thomson's experiment.

The impregnating nitrous mixture of the foregoing experiments was not destitute of nitric oxide; but what proves that the efficiency of the mixture did not depend upon the last-mentioned ingredient is the circumstance that the mixture lost its virtue by standing over mercury for a week, during which period the acid vapour was absorbed by the mercury, but the nitric oxide remained, as appeared on admitting air to the gaseous mixture. Hence we may conclude, that when nitric oxide acts in producing inflammability in phosphuretted hy- 
drogen, it is from the nitrous acid which it occasionally contains It is certainly not a little curious that nitric oxide is not equivalent to nitrous acid in producing the change in question upon phosphuretted hydrogen, seeing that the nitric oxide passes immediately into nitrous acid upon meeting air. Whether the negative influence of nitric oxide upon really accendible gas is sufficient to account for this anomaly, $I$ am doubtful. It may be thought that nitrous acid and phosphuretted hydrogen when in contact for a short time, react upon each other, with the production of some entirely new and highly accendible body. But this supposition seems not to quadrate with the fact that the impregnating mixture requires to be diluted by so large a proportion of phosphuretted hydrogen before the whole becomes spontaneously inflammable; nor is it supported by any visible signs of reaction between the nitrous acid and phosphuretted hydrogen. Indeed, nitrous acid vapour appears to be compatible with phosphuretted hydrogen to an extent which could not have been anticipated. Again, that nitrous acid, or at least some acid compound of nitrogen, continues to exist in what we may now call nitrous phosphuretted hydrogen gas, appears to be corroborated by the properties which this self-accendible gas is found to possess.

10. Properties of Nitrous Phosphuretted Hydrogen. (1.) This gas loses its self-accendibility when kept over mercury, in a period varying from six to twenty-four hours, according to the amount of nitrous impregnation. It is remarkable that this gas continues in general for a longer time inflammable when confined over water than over mercury, which is the reverse of what occurs with the gas from phosphuret of lime.

(2.) The factitious gas is deprived of its spontaneous inflammability by charcoal and porous absorbents, by essential oils and hydro-carburets, and by amalgam of potassium, and quite as rapidly as is its natural prototype.

(3.) Phosphorous acid and concentrated sulphuric acid appear likewise to withdraw the nitrous principle, although phosphoric acid does not. The agency of these acids probably exemplifies the disposition of nitrous acid to combine with other acids. The action of potassium and of essential oils upon nitrous acid requires no explanation. Potassium has, I find, no action on pure nitric oxide in the cold.

(4.) A cubic inch of this gas, passed up into a receiver of which the inside was moistened with caustic alkali, had its accendibility sensibly impaired in fifteen minutes, but not completely destroyed in less than an hour. 
In conclusion, the statement of the above properties is abundantly sufficient to prove that a strong analogy subsists between our nitrous phosphuretted hydrogen and the selfaccendible gas which has been so long in the hands of chemists. The peculiar principle of the last, therefore, may be an oxygenated body. That principle cannot be nitrous acid, but it may be a compound of phosphorus and oxygen ( analogous to nitrous acid. In all the reactions by which selfaccendible gas is produced, we have the simultaneous formation of compounds of phosphorus and oxygen, such as the hypophosphorous and phosphoric acids. The compound $\dddot{\mathrm{P}}$ is hypothetic, however, and has not been formed directly. Its existence is only surmised from the parallelism which appears to be established between nitrogen and phosphorus, and between their compounds; phosphuretted hydrogen itself corresponding with ammonia, the phosphoric and phosphorous acids, with the nitric and hyponitious acids. The peroxide of chlorine

of Davy and Stadion ( $\ddot{C})$ corresponds with nitrous acid and with our hypothetic oxide of phosphorus, which we may speak of as the peroxide of phosphorus. The peroxide of phosphorus would appear to resemble the peroxide of chlorine in being acted on more slowly by mercury and by alkalies than is the case with nitrous acid. It is to be admitted, however, that I did not succeed in producing an inflammable phosphuretted hydrogen by the agency of peroxide of chlorine,-that there is no chlorous phosphuretted hydrogen. 'The reason is, peroxide of chlorine is incompatible with phosphuretted hydrogen, reacting upon that gas at the instant of mixture.

As to the mode in which nitrous acid vapour, in a proportion so minute, contributes to the accendibility of phosphuretted hydrogen, I have been able to form no distinct idea. The most likely conjecture is, that the nitrous acid, or resulting byponitrous acid, combines with some product of the oxygenation of phosphuretted hydrogen, and thereby disposes or promotes the occurrence of that change. The oxygenation of pure hydrogen itself under the influence of a clean plate of platinum, is not promoted in a sensible degree by any nitrous impregnation. The sulphurous and muriatic acid gases, and vapour of acetic acid, appeared to contribute nothing to the accendibility of phosphuretted hydrogen.

Summary.-It appears, then, that there are not two isomeric phosphuretted hydrogens, but that the peculiarities of the gas when spontaneously inflammable depend upon adventitious matter: 
That some oxide of nitrogen, which in the present state of our knowledge of that class of compounds seems to be the nitrous acid, is capable of rendering phosphuretted hydrogen spontaneously inflammable, when that oxide is present to the extent of one ten-thonsandth part of the volume of the gas:

That such gas has a general resemblance to phosphuretted hydrogen as obtained in the spontaneously inflammable state by ordinary processes, which last probably owes its ready accendibility to the presence of an equally minute trace of a volatile compound of phosphorus and oxygen, analogous to nitrous acid.

LVIII. Observations on Magnetic Substances. By Mr. DAvid LYON.*

TRON was for a long space of time the only substance which

was known to be capable of exhibiting magnetic phænomena. It was afterwards tound that two other metals, nickel and cobalt, are endowed with a similar capacity.

Hence it appears that magnetism is not a peculiar essence of one particular substance only; and that whatever be its nature, it is not confined to one substance alone, but is common to different chemical elements. It may, therefore, be properly inquired, whether in any principal qualities, or in the numerical values of qualities, these elements do resemble one another, and are likewise distinguishable from all the other elements. For if such be the case, we may come to know on what magnetism depends, or in other words, to account for its presence in these elements and in no other; although we do not enter upon the question, as to what magnetism really is, or what is its physical origin.

The atomic weights of the three magnetic elements, as stated by Berzelius, are as follows :

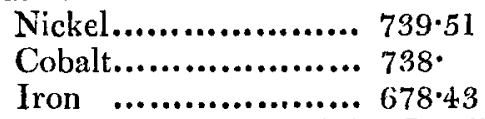

The specific gravities, as stated in Pouillet's Elémens de Physique, are,

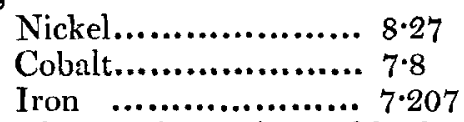

Thus, both in the atomic weights and in the specific gravities, we observe that the three magnetic substances or elements have values near together: and on inspecting the values of all the chemical elements, we observe further, that there is no

* Communicated by the Author. 